Artikel Penelitian

\title{
Isolasi dan Karakterisasi Hidroksiapatit dari Limbah Tulang Hewan
}

\author{
Vina Amalia*, Eko Prabowo Hadisantoso, Dede Hidayat, Riska Farah Diba, Muhamad Fahmi Dermawan, \\ Siti Wilamah Tsaniyah
}

Jurusan Kimia, Fakultas Sains dan Teknologi, Universitas Islam Negeri Sunan Gunung Djati Bandung

\section{INFO ARTIKEL}

Sejarah artikel

Revisi 16 September 2017

Diterima 30 Desember 2017

Tersedia online 16 Januari 2018

*Penulis korespondensi:

Email: vinaamalia@gmail.com

\begin{abstract}
ABSTRAK
Vertebrates bone contains $60 \%$ of calcium phosphate that can be used as a basic material of hydroxyapatite. Hydroxyapatite is a bioceramics material that has good adsorption properties, so it can be used as an adsorbent. This research focused on isolation and characterization of hydroxyapatite from some bone wastes, namely cow bone, goat bone, goramy and tuna fish bone. Hydroxyapatite from cow and goat bones waste was isolated by calcination at $1000^{\circ} \mathrm{C}$ and activated by $\mathrm{Na}_{2} \mathrm{CO}_{3}$. Isolation of hydroxyapatite from fish (goramy and tuna) bone waste is only hydrolyzed by $\mathrm{NaOH}$ without calcination. Characterization using XRD showed that crystalline hydroxyapatite was formed from the isolation of cow and goat bones, and amorphous hydroxyapatite was formed from the isolation of goramy and tuna fish bones. Comparison of $\mathrm{Ca} / \mathrm{P}$ of hydroxyapatite isolated from bovine, goat, goramy and tuna bones are $1.71 ; 1.79 ; 1.97 ; 1.86$, respectively. Based on IR spectra, hydroxyapatite has the $-\mathrm{OH}, \mathrm{PO}_{4}^{3-}$, and $\mathrm{CO}_{3}{ }^{2-}$ groups. The surface morphology of the hydroxyapatite is porous with the particle size of 1-2 $\mu \mathrm{m}$.
\end{abstract}

Keywords: hydroxyapatite, bone's waste, adsorbent

Tulang vertebrata mengandung $60 \%$ kalsium fosfat. yang dapat dimanfaatkan sebagai bahan dasar hidroksiapatit. Hidroksiapatit merupakan material biokeramik yang memiliki sifat adsorpsi yang baik sehingga dapat dimanfaatkan sebagai adsorben. Penelitian ini bertujuan untuk mengisolasi dan mengkarakterisasi hidroksiapatit dari beberapa limbah tulang, yaitu tulang sapi, kambing, gurame, dan tongkol. Hidroksiapatit dari limbah tulang sapi dan kambing diisolasi dengan cara kalsinasi pada suhu $1000^{\circ} \mathrm{C}$ dan diaktivasi menggunakan $\mathrm{Na}_{2} \mathrm{CO}_{3}$. Isolasi hidroksiapatit dari limbah tulang gurame dan tulang tongkol tidak dilakukan kalsinasi hanya digunakan hidrolisis menggunakan $\mathrm{NaOH}$. Karakterisasi menggunakan XRD menunjukkan bahwa telah terbentuk hidroksiapatit kristalin dari hasil isolasi tulang sapi dan kambing, dan terbentuk hidroksiapatit amorf dari hasil isolasi tulang gurame dan tongkol. Perbandingan $\mathrm{Ca} / \mathrm{P}$ hidroksiapatit hasil isolasi dari tulang sapi, kambing, gurame, dan tongkol, masing-masing adalah 1,$71 ; 1,79 ; 1,97$ dan 1,86. Spektra IR hidroksiapatit menunjukkan adanya gugus $-\mathrm{OH}$, $\mathrm{PO}_{4}{ }^{3-}$, dan $\mathrm{CO}_{3}{ }^{2-}$. Morfologi permukaan hidroksiapatit hasil isolasi berpori dengan ukuran partikel 1-2 $\mu \mathrm{m}$.

Kata Kunci: hidroksiapatit, limbah tulang, adsorben 


\section{Pendahuluan}

Hidroksiapatit $\quad\left(\mathrm{Ca}_{10}\left(\mathrm{PO}_{4}\right)_{6}(\mathrm{OH})_{2}\right) \quad$ adalah mineral anorganik yang bisa didapatkan dalam tulang, diantaranya adalah tulang hewan. Tulang adalah salah satu hasil samping selain dagingnya, tulang sapi dapat dimanfaatkan untuk keperluan yang beraneka ragam. Tulang merupakan salah satu dari bagian hewan yang memiliki banyak manfaat. Namun pemanfaatan tulang tersebut kurang optimal. Oleh karena itu, diperlukan alternatif lain untuk meningkatkan nilai ekonomis dan daya guna tulang (Atmoko \& Pangestuti, 2011). Salah satu contohnya adalah pemanfaatan tulang sapi sebagai material penyerap (adsorben) pada proses adsorpsi.

Tulang mengandung unsur seperti kalsium dan fosfor. Kalsium yang terkandung dalam tulang berupa $7,07 \% \mathrm{CaCO}_{3}, 1,96 \% \mathrm{CaF}_{2}$, dan $58,30 \%$ $\mathrm{Ca}_{3}\left(\mathrm{PO}_{4}\right)_{2}$. Adapun kandungan fosfor dalam tulang adalah $2,09 \% \quad \mathrm{Mg}_{3}\left(\mathrm{PO}_{4}\right)_{2}$ dan 58,30\% $\mathrm{Ca}_{3}\left(\mathrm{PO}_{4}\right)_{2}$ (Perwitasari, 2008). Kalsium dan fosfor merupakan unsur utama pembentuk hidroksiapatit sehingga tulang dapat dimanfaatkan sebagai bahan baku dalam sintesis hidroksiapatit. Dari kandungan kimia tersebut, maka tulang hewan dapat dimanfaatkan sebagai adsorben pada proses adsorpsi (Agarwal \& Gupta, 2015).

Potensi ini sangat bermanfaat, terutama jika diterapkan dalam upaya mengatasi pencemaran limbah berbahaya yang berasal dari industri maupun rumah tangga, diantaranya adalah pencemaran logam berat. Beberapa penelitian telah melaporkan penggunaan tulang hewan sebagai adsorben, diantaranya penggunaan arang tulang hewan sebagai adsorben logam $\mathrm{Cr}(\mathrm{VI})$ (Agarwal \& Gupta, 2015) dan penghilangan logam $\mathrm{Zn}(\mathrm{II})$ dengan menggunakan serbuk tulang ikan (Lim, Teng, Ibrahim, Ahmad, \& Chee, 2012).

Hidroksiapatit dari tulang hewan dapat disintesis dengan beberapa cara, diantaranya dengan metode Sol-Gel (Pinangsih, Wardhani, \& Darjito, 2014) basah-pengendapan (Wardhani, 2014), wet process (Fitriawan, Amalia, Saputra, Setyawati, Yulianto, \& Aji, 2015), dan hidrolisis asam (Sobczak, Kowalski, \& Wzorek, 2009), maupun hidrolisis basa (Barakat, Khil, Omran, Sheikh, \& Kim, 2009). Pada penelitian ini akan dilakukan isolasi hidroksiapatit dari beberapa limbah tulang hewan, diantaranya tulang sapi, kambing, gurame, dan tongkol. Hidroksiapatit diisolasi dari tulang sapi dan kambing dengan cara kalsinasi pada suhu $1000^{\circ} \mathrm{C}$ dan aktivasi menggunakan $\mathrm{Na}_{2} \mathrm{CO}_{3}$. Isolasi hidroksiapatit dari tulang gurame dan tulang tongkol dilakukan menggunakan hidrolisis $\mathrm{NaOH}$. Hidroksiapatit hasil isolasi dikarakterisasi menggunakan XRD (X-Ray Diffraction), XRF (X-Ray Fluoresence), FTIR (Fourier Transform Infra Red), dan SEM (Scanning Electron Microscope).

\section{Bahan dan metode}

\subsection{Bahan}

Bahan-bahan yang digunakan dalam penelitian ini antara lain limbah tulang sapi, kambing, ikan gurame, dan ikan tongkol yang diperoleh dari pasar tradisional dan pedagang kaki lima, $\mathrm{Na}_{2} \mathrm{CO}_{3}$ (Merck), dan $\mathrm{NaOH}$ (Merck).

\subsection{Preparasi dan pembuatan adsorben tulang sapi dan tulang kambing}

Sampel limbah tulang sapi dan tulang kambing dibersihkan dari daging dan sumsum yang masih berada pada tulang. Tulang dicuci dengan air dan detergen beberapa kali lalu dibilas dengan aquadest, kemudian dijemur selama satu hari sampai kering dan tidak berbau. Tulang kering digerus dan serbuk tulang ditempatkan pada cawan penguap untuk dipanaskan dengan furnace selama 1 jam pada suhu $1000{ }^{\circ} \mathrm{C}$. Setelah itu hidroksiapatit didinginkan dalam desikator.

Adsorben yang dihasilkan dari proses kalsinasi tersebut digerus hingga halus dan diayak menggunakan ayakan $149 \mu \mathrm{m}$. Selanjutnya dilakukan aktivasi, yaitu dengan menimbang sebanyak 0,5 gram adsorben tulang sapi dimasukkan ke dalam gelas kimia $250 \mathrm{~mL}$, kemudian diaktivasi dengan menambahkan larutan $\mathrm{Na}_{2} \mathrm{CO}_{3} \quad 0,1 \mathrm{M}$ sebanyak $150 \mathrm{~mL}$ di dalam gelas kimia $250 \mathrm{~mL}$. Setelah itu, campuran diaduk selama 5 menit dan dipanaskan dengan menggunakan hotplate selama 1 jam. Kemudian hidroksiapatit tersebut disaring dan dibilas dengan aquades. Setelah itu, hidroksiapatit dioven pada suhu $110^{\circ} \mathrm{C}$ selama 2 jam.

\subsection{Preparasi dan pembuatan adsorben tulang gurame dan tongkol}

Sampel tulang ikan gurame dan tongkol dibersihkan dan dicuci dengan akuades panas. Sampel yang sudah bersih didiamkan sampai kering dan dioven dengan suhu $120^{\circ} \mathrm{C}$. Sampel didinginkan dan diaktivasi. 
Serbuk tulang ikan direndam dalam larutan $\mathrm{NaOH} \mathrm{0,1} \mathrm{M} \mathrm{dengan} \mathrm{perbandingan} \mathrm{padatan:larutan}$ 1:50 (w/v) dan diaduk dengan magnetic stirer dengan kecepatan $150 \mathrm{rpm}$ selama 2 jam. Adsorben selanjutnya disaring dan dikeringkan dalam oven pada suhu $80^{\circ} \mathrm{C}$ selama 24 jam, lalu didinginkan dalam desikator. Setelah itu, adsorben ditumbuk sampai $149 \mu \mathrm{m}$. Adsorben yang telah siap digunakan disimpan dalam wadah kedap udara.

\subsection{Karakterisasi hidroksiapatit}

Instrumen yang digunakan untuk karakterisasi hidroksiapatit yang dihasilkan menggunkan SEM (JEOL JCM 6000), Spektrofotometer FTIR (Agilent Tipe Carry 600 Series), dan XRD (PANanalytical type X'Pert PRO PW3040/X0).

\section{Hasil dan pembahasan}

\subsection{Preparasi dan isolasi hidroksiapatit dari limbah tulang sapi dan kambing}

Hidroksiapatit dari tulang sapi dan tulang kambing diisolasi dengan cara dekomposisi termal. Kalsinasi dilakukan pada suhu $1000^{\circ} \mathrm{C}$, pada suhu di bawah $1000^{\circ} \mathrm{C}$ yang akan terjadi adalah proses karbonisasi senyawa organik dalam tulang. Selain adanya hidroksiapatit, akan terbentuk pula karbon. Pada suhu $1000^{\circ} \mathrm{C}$ dekomposisi senyawa organik telah sempurna terjadi sehingga yang tertinggal hanya tinggal mineral pada tulang. Karena kandungan mineral tertinggi hidroksiapatit, maka pada suhu ini terbentuk hidroksiapatit dengan optimum. Hasil kalsinasi tulang sapi dan kambing pada suhu $1000^{\circ} \mathrm{C}$ menghasilkan tulang dengan warna yang putih, seperti ditunjukkan pada Gambar 1. Randemen hidroksiapatit hasil isolasi dari tulang didapatkan sebesar $58,6 \%$. Pada suhu di atas $1000^{\circ} \mathrm{C}$, akan terbentuk trikalsium fosfat sebagai hasil dekomposisi hidroksiapatit.

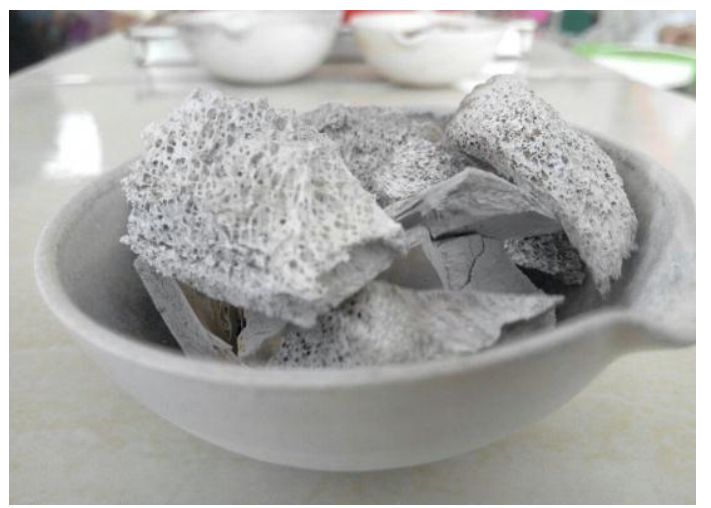

Gambar 1. Tulang sapi yang sudah dikalsinasi
Proses pengayakan bertujuan untuk mendapatkan ukuran partikel yang lebih kecil dan homogen, sehingga luas permukaan adsorben semakin besar. Ukuran partikel berpengaruh terhadap proses adsorpsi sehingga serbuk tulang yang berukuran $149 \mu \mathrm{m}$ lebih efektif untuk dijadikan adsorben. Apabila ukuran partikel diperkecil maka permukaan adsorben menjadi lebih luas sehingga lebih banyak permukaan adsorben yang siap untuk berinterasi dengan aktivator maupun dengan adsorbat dan proses adsorpsi akan lebih optimal.

Tujuan dari proses aktivasi adalah untuk membuka pori-pori hidroksiapatit dengan cara melarutkan pengotor yang masih terdapat dalam hidroksiapatit. Pemilihan aktivator $\mathrm{Na}_{2} \mathrm{CO}_{3}$ ini karena dibandingkan dengan $\mathrm{H}_{3} \mathrm{PO}_{4}$ dan $\mathrm{NaOH}$, senyawa yang terbentuk antara ion karbonat dengan logam-logam mineral yang masih terdapat dalam hidroksiapatit memiliki kelarutan yang lebih besar. Oleh karena itu, pada saat proses aktivasi dilakukan, logam-logam tersebut dimungkinkan dapat terlarut dan pori-pori hidroksiapatit menjadi lebih terbuka.

\subsection{Preparasi dan isolasi hidroksiapatit dari limbah tulang gurame dan tongkol}

Hidroksiapatit dari limbah tulang ikan gurame dan tongkol diisolasi dengan cara hidrolisis basa. Hidrolisis basa merupakan alternatif isolasi hidroksiapatit selain dengan cara dekomposisi termal. Selain mengandung hidroksiapatit, tulang juga mengandung kolagen. Dengan cara hidrolisis basa, kolagen dan senyawa organik lainnya yang terdapat dalam tulang akan terdekomposisi (Barakat et al., 2009).

Pada umumnya, adsorben tulang ikan memiliki daya adsorpsi rendah sehingga untuk mendapatkan adsorben yang mempunyai daya adsorpsi tinggi perlu dilakukan proses aktivasi. Proses yang dilakukan yaitu dengan menggunakan aktivator $\mathrm{NaOH}$ 0,1 M. Aktivasi ini bertujuan untuk memperbesar pori yaitu dengan cara memecahkan ikatan hidrokarbon atau mengoksidasi molekulmolekul permukaan sehingga serbuk tulang mengalami perubahan, yaitu luas permukaan bertambah besar dan berpengaruh terhadap daya adsorpsi. 


\subsection{Karakterisasi hidroksiapatit hasil isolasi}

\subsubsection{Hasil karakterisasi XRD}

Analisis XRD diperlukan untuk menentukan senyawa anorganik dan struktur kristal dari suatu material. Hasil analisis XRD (Gambar 2) menunjukkan bahwa hidroksiapatit hasil isolasi memiliki kesamaan $2 \theta$ puncak tertinggi dengan hidroksiapatit standar (Calculated from ICSD using POWD-12++) yaitu pada 20: 25,867; 31,765; 32,$183 ; 32,899,39,794 ; 46,687$.

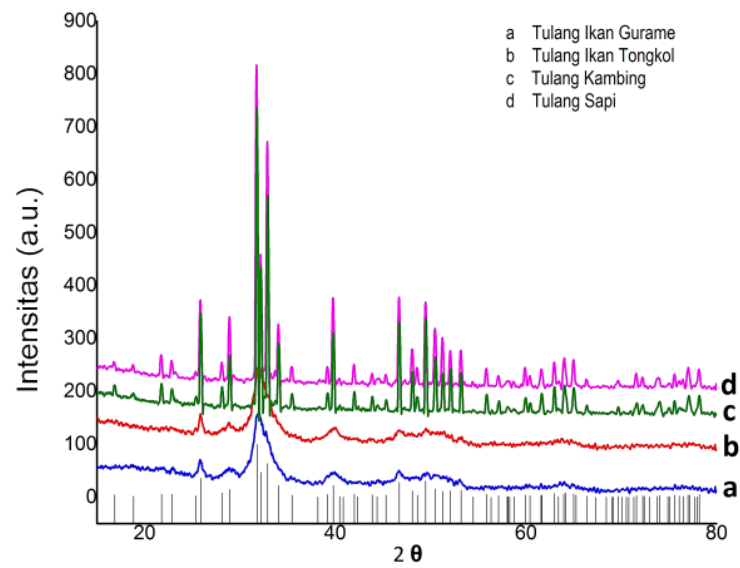

Gambar 2. Spektrum XRD hidroksiapatit hasil isolasi

Dari spektrum XRD terlihat bahwa hidroksiapatit yang diisolasi dari tulang sapi dan kambing dengan cara kalsinasi memiliki kristalinitas yang sangat besar. Berbeda dengan hidroksiapatit hasil isolasi dari tulang gurame dan tongkol yang dilakukan dengan metode hidrolisis $\mathrm{NaOH}$, memiliki kristalinitas yang rendah. Hal ini menunjukkan bahwa suhu isolasi akan berpengaruh terhadap struktur kristal hidroksiapatit yang terbentuk. Semakin tinggi suhu dekomposisi menyebabkan kristalinitas dari hidroksiapatit semakin besar (Zanotto, Saladino, Martino, \& Caponetti, 2012).

\subsubsection{Hasil karakterisasi XRF}

Kandungan unsur yang terdapat dalam hidroksiapatit dapat dilihat pada Tabel 1. Secara umum kandungan terbesar dari hidroksiapatit adalah unsur $\mathrm{Ca}$ dan $\mathrm{P}$. Pada hidroksiapatit komersial $\mathrm{Ca}_{10}\left(\mathrm{PO}_{4}\right)_{6}(\mathrm{OH})_{2}$, perbandingan $\mathrm{Ca} / \mathrm{P}$ adalah 1,67 sedangkan perbandingan $\mathrm{Ca} / \mathrm{P}$ dari hidroksiapatit hasil isolasi menunjukkan nilai 1,71 ; 1,$79 ; 1,97 ; 1,86$. Nilai ini lebih besar dari rasio yang seharusnya, hal tersebut dimungkinkan karena masih adanya senyawa lain dalam bentuk senyawa kalsium dalam hidroksiapatit hasil isolasi. Senyawa kalsium yang mungkin terbentuk adalah $\mathrm{CaCO}_{3}$ dan $\mathrm{CaO}$ (Pinangsih et al., 2014)

Tabel 1.

Kandungan unsur dalam hidroksiapatit hasil isolasi

\begin{tabular}{|c|c|c|c|c|}
\hline \multirow[b]{2}{*}{ Unsur } & \multicolumn{4}{|c|}{ Massa (\%) } \\
\hline & $\begin{array}{c}\text { Tulang } \\
\text { Sapi }\end{array}$ & $\begin{array}{c}\text { Tulang } \\
\text { Kambing }\end{array}$ & $\begin{array}{l}\text { Tulang } \\
\text { Gurame }\end{array}$ & $\begin{array}{l}\text { Tulang } \\
\text { Tongkol }\end{array}$ \\
\hline Si & 0,1090 & 0,1150 & 0,0809 & 0,0555 \\
\hline $\mathrm{Ti}$ & - & 0,0034 & 0,0035 & 0,0029 \\
\hline Al & 0,0183 & 0,0503 & 0,0340 & 0,0263 \\
\hline $\mathrm{Fe}$ & 0,0144 & 0,0129 & 0,0138 & 0,0271 \\
\hline Mn & - & . & 0,0070 & 0,0033 \\
\hline $\mathrm{Ca}$ & 38,6800 & 39,3500 & 27,5600 & 26,300 \\
\hline $\mathrm{Mg}$ & 1,0400 & 1,0000 & 0,4830 & 0,5340 \\
\hline $\mathrm{Na}$ & 0,8720 & 1,3500 & 0,3480 & 0,2550 \\
\hline K & 0,0295 & 0,0192 & 0,0192 & 0,0779 \\
\hline $\mathbf{P}$ & 17,4700 & 16,9800 & 10,8100 & 10,9100 \\
\hline $\mathbf{S}$ & 0,0126 & 0,0225 & 0,0494 & 0,0913 \\
\hline $\mathrm{Ca} / \mathrm{P}$ & 1,71 & 1,79 & 1,97 & 1,86 \\
\hline
\end{tabular}

\subsubsection{Hasil Karakterisasi FTIR}

Berdasarkan analisis spektrum IR (Gambar 3), diketahui bahwa hidroksiapatit memiliki gugus $\mathrm{OH}$ dan $\mathrm{PO}_{4}{ }^{3-}$. Selain itu, ada juga gugus $\mathrm{CH}$ dan gugus $\mathrm{CO}_{3}{ }^{2-}$ pada hidroksiapatit hasil isolasi dari tulang gurame dan tongkol. Munculnya puncak di bilangan gelombang gugus $\mathrm{CH}$ dan $\mathrm{CO}_{3}{ }^{2-}$ mengindikasikan bahwa dalam hidroksiapatit tersebut masih terdapat senyawa organik dan senyawa karbonat yang belum terdekomposisi.

Masih terdapatnya kolagen yang tidak terdekomposisi dapat terlihat dari munculnya puncak pada 1550 (regangan $\mathrm{N}-\mathrm{H}$ ) dan 2922 (regangan $\mathrm{C}-\mathrm{H}$ ). Adapun keberadaan diidentifikasi dari munculnya puncak pada bilangan gelombang 1663 (regangan $\mathrm{C}=0$ ) dan 1027 ( regangan C-OC) (Lim et al., 2012).

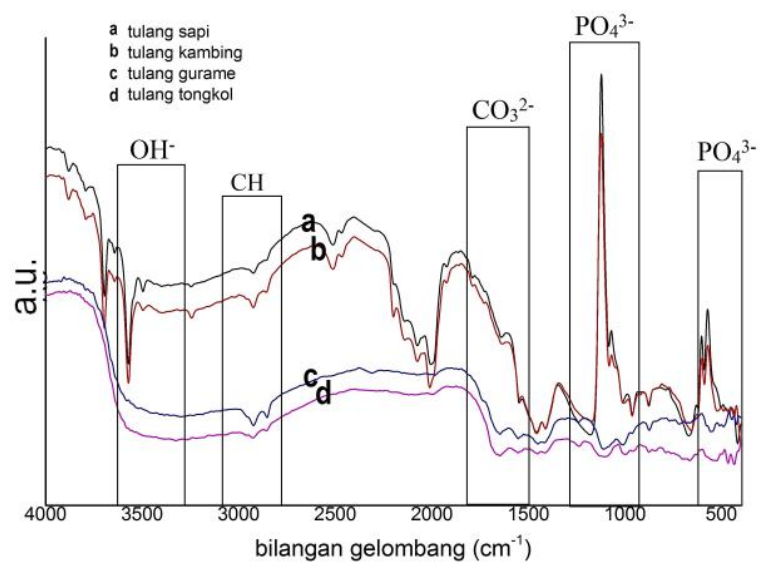

Gambar 3. Spektrum FTIR hidroksiapatit hasil isolasi 

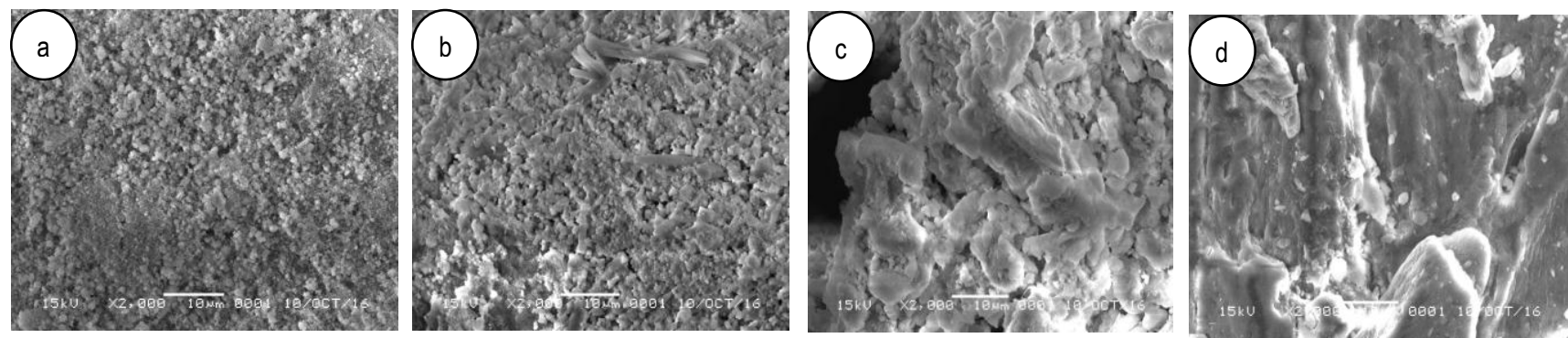

Gambar 4. Morfologi permukaan hidroksiapatit hasil isolasi dari tulang (a) sapi, (b) kambing, (c) gurame, dan (d) tongkol dengan perbesaran 2000 kali.

\subsubsection{Hasil karakterisasi SEM}

Morfologi permukaan hidroksiapatit hasil isolasi diperlihatkan pada Gambar 4. Berdasarkan gambar tersebut diketahui keberadaan pori pada permukaan hidroksiapatit. Ukuran partikel hidroksiapatit tulang sapi dan kambing sekitar 1-2 $\mu \mathrm{m}$ dan memiliki bentuk yang seragam, sedangkan ukuran dari partikel hidroksiapatit tulang gurame dan tongkol berukuran lebih besar serta tidak beraturan.

Perbedaan suhu isolasi menyebabkan perbedaan ukuran dan bentuk kristal hidroksiapatit yang terbentuk. Hidroksiapatit yang disintesis pada suhu di atas $900^{\circ} \mathrm{C}$ memiliki morfologi batang heksagonal yang beraturan. Adapun hidroksiapatit yang terbentuk pada suhu di bawah $900^{\circ} \mathrm{C}$ memiliki morfologi kristal berbentuk jarum (Zanotto et al., 2012).

\section{Kesimpulan}

Hidroksiapatit dapat diisolasi dari limbah tulang dengan cara kalsinasi tanpa penambahan pelarut (tulang sapi dan kambing) dan dengan cara hidrolisis $\mathrm{NaOH}$ (tulang gurame dan tongkol). Hasil karakterisasi XRD menunjukkan bahwa terbentuk hidroksiapatit dengan kristalinitas yang berbeda tergantung dari metode isolasi. Rasio $\mathrm{Ca} / \mathrm{P}$ hidroksiapatit hasil isolasi menunjukkan nilai 1,71 ; 1,$79 ; 1,97 ; 1,86$ masing-masing pada tulang sapi, kambing, gurame, dan tongkol. Partikel hidroksiapatit yang diperoleh dari isolasi dengan cara kalsinasi memiliki ukuran yang lebih kecil dan lebih seragam dibandingkan dengan hasil hidrolisis basa.

\section{Ucapan Terima Kasih}

Ucapan terima kasih ditujukan kepada Diktis Kemenag yang telah memberikan bantuan dana penelitian.

\section{Daftar Pustaka}

Agarwal, A., \& Gupta, P. K. (2015). Adsorption study of $\mathrm{Cr}(\mathrm{II})$ from aqueous solution using animal bone charcoal as low cost adsorbent. International Journal of Engineering Technology, Management and Applied Sciences, 3(1), 151-163.

Atmoko, I. D., \& Pangestuti, R. D. (2011). Produksi gelatin dari tulang sapi dengan proses hidrolisa. Semarang. Retrieved from http://eprints.undip.ac.id/36784/

Barakat, N. A. M., Khil, M. S., Omran, A. M., Sheikh, F. A., \& Kim, H. Y. (2009). Extraction of pure natural hydroxyapatite from the bovine bones bio waste by three different methods. Journal of Materials Processing Technology, 209(7), 3408-3415.

Fitriawan, M., Amalia, S.R., Saputra, B.A., Setyawati, E., Yulianto, A., \& Aji, M.P. (2015). Sintesis hidroksiapatit berbahan dasar tulang sapi dengan metode presipitasi sebagai kandidat pengganti graft berdasarkan compressive strength. In Prosiding Seminar Nasional Mahasiswa Fisika 2014, Semarang.

Lim, H.K., Teng, T.T., Ibrahim, M.H., Ahmad, A., \& Chee, H.T. (2012). Adsorption and removal of Zinc (II) from aqueous solution using powdered fish bones. APCBEE Procedia, 1 , 96-102. 
Perwitasari, D.S. (2008). Hidrolisis tulang sapi menggunakan $\mathrm{HCl}$ untuk pembuatan gelatin. In Makalah Seminar Nasional Soebardjo Brotohardjono "Pengolahan Sumber Daya Alam dan Energi Terbarukan" (pp. 1-9). Retrieved from https://core.ac.uk/download/pdf/12218210. pdf

Pinangsih, A. C., Wardhani, S., \& Darijto. (2014). Sintesis biokeramik hidroksiapatit $\left(\mathrm{Ca}_{10}\left(\mathrm{PO}_{4}\right)_{6}(\mathrm{OH})_{2}\right)$ dari limbah tulang sapi menggunakan metode sol-gel. Kimia Student Journal, 1(2), 203-209.
Sobczak, A., Kowalski, Z., \& Wzorek, Z. (2009). Preparation of hydroxyapatite from animal bones. Acta of Bioengineering and Biomechanics, 11(4), 23-28.

Wardhani, S. (2014). Sintesis hidroksiapatit dari tulang sapi dengan metode basahpengendapan. Kimia Student Journal, 1(1), 92-97.

Zanotto, A., Saladino, M. L., Martino, D. C., \& Caponetti, E. (2012). Influence of temperature on calcium hydroxyapatite nanopowders. Advances in Nanoparticles, 1(3), 21-28. 